\title{
Medical and Mental Health Comorbidities Among Minority Racial/Ethnic Groups in the United States
}

\author{
Naheed Ahmed, PhD \\ University of Maryland School of Public Health, College Park, Maryland, United States \\ (iD) https://orcid.org/0000-0002-5980-8480 \\ C. Andrew Conway, MSW \\ University of Maryland School of Public Health, College Park, Maryland, United States \\ (iD) https://orcid.org/0000-0003-3606-2871
}

Contact: nahmed12@umd.edu

\section{Abstract}

The objective of this study was to examine the prevalence of and the association between comorbid disorders and race/ethnicity in the United States. Using cross-sectional data from the 2012 Behavioral Risk Factor Surveillance System $(N=45,207,844)$, we examined the comorbidity of psychological distress with self-reported diagnosis of diabetes and angina and history of heart attack and stroke. Logistic regression was used to examine between group differences by race/ethnicity. Unadjusted results indicate that American Indian (odds ratio [OR] $=4.01,95 \%$ confidence interval [CI] [1.78, 9.04]) and Hispanic $(O R=1.55,95 \% \mathrm{CI}[1.04,2.33])$ participants were more likely to have psychological distress and history of heart attack in comparison to White participants. American Indians were more likely to have psychological distress with angina $(O R=3.82,95 \%$ CI $[1.92,7.63])$ and with history of stroke $(O R=4.25$, 95\% CI [2.16, 8.26]) in unadjusted results when compared to White participants. Our results suggest that racial/ethnic minority groups, compared to White Americans, are more likely to suffer from comorbid mental health and medical conditions, which may be a result of stress arising from discrimination and historical oppression of these populations.

Keywords: health inequalities, depression, diabetes, heart disease

Date Submitted: February 14, 2020 | Date Published: June 23, 2020

\section{Recommended Citation}

Ahmed, N., \& Conway, C. A. (2020). Medical and mental health comorbidities among minority racial/ethnic groups in the United States. Journal of Social, Behavioral, and Health Sciences, 14, 153-168. https://doi.org/10.5590/JSBHS.2020.14.1.11 


\section{Introduction}

Public health researchers have investigated health disparities among racial/ethnic minority populations in the United States over the past several decades to determine if minorities are disproportionately overrepresented in poor health outcomes, examining a range of health issues from maternal and child health to chronic diseases (National Center for Health Statistics, 2016; Orsi et al., 2010). The underlying reasons for these health trends are interconnected and complex including risk factors such as diet, physical activity levels, and genetics (Pool et al., 2017; Stamler et al., 1993). For minority racial/ethnic populations, stress arising from discrimination may play a role in terms of the physiological response to chronic stress, which has been linked to poor health outcomes among minority populations (Carter et al., 2017; Gee et al., 2007; Williams 2018). Additionally, discrimination can have community level impact by influencing availability of housing options, food insecurity, and access to health services, all of which are shown to be associated with poor health outcomes (Knapp \& Hall, 2018; Kolak et al., 2020).

Few studies have examined the relation between race/ethnicity and the compounding effects of mental health and chronic conditions (Garcini et al., 2017). Given the stress from discrimination arising from minority status in the United States, the mental health effects among minorities with chronic conditions may be further exacerbated due to frequent encounters with discrimination in school, workplace, and health care settings. The stress from discriminatory treatment arising from minority status in the United States has significant implications for the health of racial/ethnic minority groups. Previous studies have demonstrated the link between stress and adverse health outcomes, including preterm birth, depression, and hypertension (Earnshaw et al., 2016; Gavin et al., 2019; Mouzon et al., 2017). Furthermore, individuals with a mental health disorder are more likely to be diagnosed with diabetes or cardiovascular disease, and vice versa (Goodell et al., 2011; Watkins et al., 2015). Building on existing research on this topic, this study explored the association between mental and medical comorbidities by racial/ethnic minority groups using national health data from the U.S. Centers for Disease Control and Prevention (CDC).

\section{Comorbid Mental and Medical Conditions}

There is an established bidirectional relationship between mental health and medical outcomes, resulting in comorbidity of these conditions (Rustad et al., 2011). The biological pathway underlying these comorbidities is unknown, but scientists hypothesize that the inflammation associated with certain conditions may be a contributing factor, as well as side effects from prescription drugs for these conditions, which may include psychological symptoms and weight gain (Miller \& Raison, 2016; Rustad et al., 2011). Common mental and medical comorbidities include depression with diabetes, and depression with cardiovascular disease (Druss et al., 2011). Past studies have shown that patients with depression have an increased risk for developing diabetes (41\% for Type I and 32\% for Type II diabetes; Roy \& Lloyd, 2012). Similarly, depression is associated with increased risk for cardiovascular disease and worse health outcomes after a cardiovascular event (heart attack, stroke; Bradley \& Rumsfeld, 2015).

Few studies have examined the association between comorbid mental and medical conditions and racial/ethnic minority groups; among those that have, there are mixed results. Watkins and colleagues (2015) used data from the National Survey of American Life to examine group differences in comorbid mental and chronic medical conditions, though they only investigated differences among African American, Caribbean Black, and non-Hispanic White participants. The results indicated that an individual's race and ethnicity may play a role in comorbid mental and medical disorders, specifically that major depression was associated with at least one chronic medical condition among African American and Caribbean Black participants, but not for non-Hispanic White participants (Watkins et al., 2015). Carliner and colleagues (2014) reported mixed results in a review of 40 different comorbidity studies, which suggested that while some risk factors associated with cardiovascular diseases were associated with racial/ethnic minority groups, the overall association between 
comorbidity of cardiovascular diseases and mental health disorders among racial/ethnic minority groups was inconclusive. The authors concluded that there is evidence to suggest that risk for cardiovascular disease may vary among racial/ethnic groups by mental illness status. The mixed and at times conflicting results in the literature and the lack of specific studies investigating the associations between mental health and medical comorbidities and racial/ethnic minority groups point to the need for further investigation.

\section{Theoretical Framework}

In an editorial for The British Journal of Psychiatry, Das-Munshi and colleagues (2016) proposed using the "double jeopardy" hypothesis as a framework for understanding increased risk for comorbid mental health and medical conditions among racial and ethnic minority populations. Developed in 1970, the "double jeopardy" hypothesis was originally used to describe how the status of race/ethnicity and old age lead to poorer health among elderly African Americans compared with elderly White Americans. Researchers have extended the "double jeopardy" hypothesis over the years to describe how having two (or more) stigmatized identities leads to being "doubly (or multiply) disadvantaged," which in turn results in worse overall health than those living with one or no stigmatized identities (Das-Munshi et al., 2016). Using "double jeopardy," it is hypothesized that the stigma and discrimination associated with being a racial/ethnic minority is then compounded by the stigma associated with mental illness resulting in worse physical health outcomes, and thus greater likelihood of comorbid mental and chronic medical conditions in these populations. There have been minimal studies able to test this hypothesis and those that have tend to use small sample sizes (Mangurian et al., 2016).

Based on the existing literature linking mental health to chronic conditions among racial/ethnic minority groups and grounded in the "double jeopardy" hypothesis, this study examined comorbidity of psychological distress with diagnosis of diabetes, angina, history of heart attack, or stroke using national health data from the CDC's Behavioral Risk Factor Surveillance System (BRFSS). Psychological distress as measured using the Kessler Psychological Distress Scale was selected because it provides a current assessment of psychological distress status. The BRFSS survey only asks one question about self-reported diagnosis of any mental health condition; however, the question does not include a time component and thus it is not possible to determine if respondents have an active diagnosis, so this question was excluded from the analysis. Diagnosis of diabetes or angina, and history of heart attack or stroke were selected as medical outcomes to be examined in this study as these conditions require ongoing medical care, which may include routine doctor visits, lifestyle changes, and prescription and over the counter drugs (American Diabetes Association, 2018; Mangurian et al., 2016; Sjöström et al., 2004). The research aims of this study were to (a) describe the prevalence of comorbid health conditions by race/ethnicity in the United States and (b) examine the association between race/ethnicity and comorbid health outcomes in the United States.

Hypothesis: Minority racial/ethnic participants will be more likely to have comorbid health conditions in comparison to White participants.

\section{Method}

Data from the 2012 BRFSS were analyzed for this study (Silva, 2014). The CDC collects BRFSS data from all 50 U.S. states, Guam, and Puerto Rico via telephone surveys (landline and mobile phone). The BRFSS uses a core standardized health questionnaire in each state and territory, which asks respondents 18 years and older about health-related risk behaviors, chronic health conditions, and use of preventive health services. States and territories may include optional health modules in the questionnaire on topics such as health literacy, mental health, discrimination, and asthma. The 2012 dataset was selected for analysis because it included the largest number of states using the optional survey module on mental health in the past 6 years. A total of 11 states/territories included the mental health module: Illinois, Iowa, Minnesota, Missouri, Montana, Nevada, 
New Mexico, New York, Oregon, Puerto Rico, and Washington. This study was approved by the University of Maryland's Institutional Review Board on March 1, 2019.

\section{Measures}

\section{Independent variables}

Participants were asked to select their race/ethnicity using the following options: White, Black, Asian, Hispanic, American Indian, or other. Dummy variables for each race/ethnicity were created and coded as binary $($ yes $=1$, no $=0$ ).

\section{Dependent variables}

A total of four comorbid health outcomes were created from responses to the Kessler Psychological Distress Scale-6, diagnosis of diabetes, history of a heart attack, diagnosis of coronary heart disease (angina), and history of a stroke.

\section{Psychological distress}

The Kessler Psychological Distress Scale-6 asks respondents to select the frequency of emotions related to feeling nervous, hopeless, restless, depressed, worthless, and feeling that everything took a lot of effort in the past 30 days. The scale is a useful tool for assessing an individual's psychological state and was used as a proxy for depression and anxiety, but does not provide a clinical diagnosis (Kessler et al., 1999). Response options for all questions range from o (none of the time) to 4 (all the time). Total scores are calculated and range from o to 24. Based on a validation study of the K6, a score of 8 or higher indicates a participant experiencing moderate to severe psychological distress (Kessler et al., 2003). This cutoff point has also been found effective in previous research using BRFSS data (Dhingra et al., 2011). Responses were coded into a binary variable, where a score of 8 or higher coded as 1 and a score below 8 coded as 0 .

\section{Diabetes}

Participants were asked if they had ever been told that they had diabetes (yes $=1$, no $=0$ ). Female participants who indicated that the diagnosis was only when they were pregnant were coded as not having diabetes for this study.

\section{Heart attack}

Participants were asked if they had ever been told they had a heart attack or myocardial infraction (yes $=1$, no $=0$ ).

\section{Coronary heart disease}

Participants were asked if they had ever been told that they had angina or coronary heart disease (yes $=1$, no $=0)$.

\section{Stroke}

Participants were asked if they had ever been told that they had a stroke $($ yes $=1$, no $=0$ ).

\section{Comorbid physical health and psychological distress}

A comorbidity variable was created for each of the four physical morbidity variables (diabetes, history of heart attack, angina, history of heart attack). If participants responded to having psychological distress (scale score of 8 or higher on the K6) and responded to having the physical morbidity, the comorbidity variable was coded as 1 . Otherwise, the comorbidity variable was coded as 0.

\section{Covariate variables}

Categorical variables on education level (four categories: missing responses to education, some high school, some college, college), household income (four categories: missing responses to household income, $<\$ 25,000$, 
$\$ 25,000-\$ 49,999, \geq \$ 50,000$ ), age (seven categories: missing responses to age, $18-24,25-34,35-44,45-54$, 55-64, 65+), sex (binary: male or female), and health insurance status (two categories: missing responses to health insurance, have some form of health insurance) were used as covariates in the analysis.

\section{Analysis}

First, descriptive statistics were used to assess the frequency of independent, covariate, and outcome variables. Next, chi-squared tests were used to examine associations between comorbid health outcomes and each racial/ethnic group, and prevalence of these outcomes by race/ethnicity. Third, logistic regression models for each comorbid outcome were run in which the comorbid health outcome was regressed on race/ethnicity. Then we added the covariate variables to each of the models, which included age, sex, health insurance status, education level, and household income level. The reference variable for each category (e.g. race/ethnicity, income, education level) - the comparison group for the odds of having a comorbid conditionis included in the results table. The BRFSS data set uses a complex survey design and all analyses included weight, cluster, and stratification variables. Data were weighted according to the following factors: demographic characteristics (age, gender, race/ethnicity, phone ownership, number of adults in the household) and geographic region.

\section{Missing data}

We used the imputed race/ethnicity variable in the BRFSS data set and as a result there are no missing responses for race/ethnicity. "Refused to answer" and "not sure/don't know" responses were coded as missing in the data set. Covariate variables (age, sex, education, and income) were available for $86.53 \%$ of the sample. Income represented the largest source of missing data with $12.15 \%$ missing on this variable. We conducted Little's missing-completely-at-random test on the covariate variables, which was significant, meaning the "refused to answer" and "not sure/don't know" responses were not missing completely at random (Little , 1988). In light of these results, we created missing categories for each covariate variable (age, income, education, health insurance), which were made up of "refused to answer" and "not sure/don't know" responses (Little, 1988). We also conducted a sensitivity analysis, where we ran our analyses using only complete cases, and the results were similar to our analyses including missing cases.

The original sample size, including "refused to answer" and "not sure/don't know" came to 87,050. Among health outcomes of interest (diabetes, heart attack, angina, and stroke), missing data were minimal (less than $0.8 \%$ missing). From this sample, missing data was explored for the six items on the Kessler Psychological Distress Scale. A total of 80,666 participants provided complete responses to the Kessler questions. Only cases with complete health outcome data were retained. After creating missing categories for "refused to answer" and "not sure/don't know" for covariate variables, and only including complete responses to health variables the final sample size used for this article is 78,551 . The weighted sample is $45,207,844$.

\section{Results}

\section{Descriptive Statistics}

The sociodemographic characteristics of and frequency of comorbid health outcomes in the sample are detailed in Table 1 . The majority of participants have some form of health insurance (84.53\%) and less than a college level of education (73\%). The largest proportion of participants has a household income less than $\$ 75,000$ (48\%). The prevalence of comorbid health outcomes is low in the sample, ranging from $0.57 \%$ (psychological distress and history of stroke) to 1.83\% (psychological distress and diabetes). 
Table 1. Sociodemographic Characteristics and Comorbidities (Weighted Sample $\mathrm{N}=45,207,844$ )

\begin{tabular}{|c|c|c|c|c|c|}
\hline Demographic & $\begin{array}{c}N, \\
\text { unweighted }\end{array}$ & $\begin{array}{c}\%, \\
\text { weighted }\end{array}$ & Demographic & $\begin{array}{c}N, \\
\text { unweighted }\end{array}$ & $\begin{array}{c}\%, \\
\text { weighted }\end{array}$ \\
\hline Race & & & Health insurance & & \\
\hline White & 59,560 & $66.94 \%$ & Yes & 69,677 & $84.53 \%$ \\
\hline Black & 2,585 & $8.51 \%$ & No & 8,874 & $15.03 \%$ \\
\hline Asian & 1,053 & $3.97 \%$ & Refused/don't know & 232 & $0.44 \%$ \\
\hline American Indian & 1,398 & $1.00 \%$ & Income & & \\
\hline Hispanic & 11,849 & $17.67 \%$ & $<\$ 25,000$ & 21,441 & $27.03 \%$ \\
\hline Other & 2,106 & $1.90 \%$ & $\$ 25,000-49,999$ & 18,192 & $21.56 \%$ \\
\hline Age, years & & & $\geq \$ 50,000$ & 29,404 & $39.24 \%$ \\
\hline $18-24$ & 4,251 & $12.02 \%$ & Refused/don't know & 9,514 & $12.15 \%$ \\
\hline $25-34$ & 7,742 & $15 \cdot 97 \%$ & Distress and diabetes & & \\
\hline $35-44$ & 9,841 & $16.89 \%$ & Yes & 1580 & $1.83 \%$ \\
\hline $45-54$ & 13,852 & $18.88 \%$ & No & 76,971 & $98.17 \%$ \\
\hline $55^{-64}$ & 17,245 & $16.65 \%$ & Distress and heart attack & & \\
\hline 65 and up & 24,972 & $18.90 \%$ & Yes & 733 & $0.89 \%$ \\
\hline Refused/don't know & 648 & $0.68 \%$ & No & 77,818 & $99.11 \%$ \\
\hline Sex & & & Distress and angina & & \\
\hline Female & 46,578 & $52.27 \%$ & Yes & 886 & $1.04 \%$ \\
\hline Male & 31,973 & $47 \cdot 73 \%$ & No & 77,665 & $98.96 \%$ \\
\hline Education & & & Distress and stroke & & \\
\hline Less than high school & 6,434 & $13.84 \%$ & Yes & 600 & $0.57 \%$ \\
\hline Less than college & 43,713 & $59.28 \%$ & No & 77,951 & $99.43 \%$ \\
\hline College or higher & 28,262 & $26.69 \%$ & & & \\
\hline Refused/don't know & 142 & $0.19 \%$ & & & \\
\hline
\end{tabular}


The chi-squared tests for comorbidity prevalence by race/ethnicity are detailed in Table 2. Comorbid health outcomes were significantly associated with each racial/ethnic group. American Indian participants have the highest prevalence of psychological distress and diabetes (6.60\%), psychological distress and history of heart attack (2.98\%), and psychological distress and history of stroke (2.13\%). Asian participants have the highest prevalence of psychological distress and angina (1.82\%).

Table 2. Weighted Prevalence of Health Outcomes by Race/Ethnicity

\begin{tabular}{lcccc}
\hline \multicolumn{1}{c}{ Race/Ethnicity } & $\begin{array}{c}\text { Distress and } \\
\text { diabetes }\end{array}$ & $\begin{array}{c}\text { Distress and } \\
\text { heart attack }\end{array}$ & $\begin{array}{c}\text { Distress and } \\
\text { angina }\end{array}$ & $\begin{array}{c}\text { Distress and } \\
\text { stroke }\end{array}$ \\
\hline White & $1.30 \%^{* *}$ & $0.76 \%^{* *}$ & $0.84 \%^{* *}$ & $0.51 \%^{* *}$ \\
Black & $1.8 \%^{*}$ & $0.92 \%^{* *}$ & $0.44 \%^{* *}$ & $0.63 \%^{* *}$ \\
Asian & $1.76 \%^{* *}$ & $0.2 \%^{* *}$ & $1.82 \%^{* *}$ & $0.48 \%^{* *}$ \\
American Indian & $6.60 \%^{* *}$ & $2.98 \%^{* *}$ & $1.00 \%^{* *}$ & $2.13 \%^{* *}$ \\
Hispanic & $3.30 \%^{* *}$ & $1.18 \%^{* *}$ & $1.79 \%^{* *}$ & $0.61 \%^{* *}$ \\
Other & $4.38 \%^{* *}$ & $3.04 \%^{* *}$ & $1.01 \%^{*}$ & $1.20 \%^{* *}$ \\
\hline
\end{tabular}

Note. $p$ Values were obtained using chi-squared tests.

${ }^{*} p<.01 .{ }^{* *} p<.001$.

\section{Odds Ratios}

Models assessing comorbidity of psychological distress and diabetes are reported in Table 3 . In the first model, American Indian (odds ratio $[O R]=5.35$, 95\% confidence interval $[\mathrm{CI}][3.02,9.50]$ ) Hispanic $(O R=$ $2.58,95 \%$ CI $[2.11,3.16])$, and other participants $(O R=3.46$, 95\% CI $[1.39,8.64])$ were more likely to have this comorbid condition in comparison to White participants. The addition of covariate variables in Model 2 resulted in these associations remaining significant.

Results for comorbidity of psychological distress and past history of heart attack are reported in Table 4 . American Indian $(O R=4.01,95 \%$ CI [1.78, 9.04]), Hispanic $(O R=1.55,95 \%$ CI [1.04, 2.33]), and other participants $(O R=4.09,95 \% \mathrm{CI}[1.12,14.93])$ were more likely to experience psychological distress and have past history of a heart attack in comparison to White participants. The addition of covariate variables resulted in the associations no longer being significant.

Next, we assessed psychological distress and angina (Table 5). American Indian ( $O R=3.82,95 \% \mathrm{CI}[1.92$, 7.63]) and Hispanic participants ( $O R=2.15,95 \% \mathrm{CI}[1.60,2.90])$ were more likely to suffer from psychological distress and angina in comparison to White participants. Black participants were less likely (OR $=.51,95 \% \mathrm{CI}[0.27,0.97])$ to have this comorbid condition in comparison to White participants. These associations remained significant with the addition of covariate variables. 
Table 3. Psychological Distress and Diabetes

\begin{tabular}{|c|c|c|c|c|}
\hline \multirow[b]{2}{*}{ Demographic } & \multicolumn{2}{|c|}{ Model 1} & \multicolumn{2}{|c|}{ Model 2} \\
\hline & OR & $95 \% \mathrm{CI}$ & OR & $95 \% \mathrm{CI}$ \\
\hline \multicolumn{5}{|l|}{ Race/ethnicity } \\
\hline Black & 1.41 & {$[0.91,2.16]$} & 1.04 & {$[0.67,1.62]$} \\
\hline Asian & 1.35 & {$[0.33,5.42]$} & 2.15 & {$[0.48,9.54]$} \\
\hline American Indian & $5 \cdot 35^{* *}$ & {$[3.02,9.50]$} & $3.63^{* *}$ & {$[1.94,6.80]$} \\
\hline Hispanic & $2.58^{* *}$ & {$[2.11,3.16]$} & $1.67^{* *}$ & {$[1.30,2.15]$} \\
\hline Other & $3.46^{*}$ & {$[1.39,8.64]$} & $3.21^{*}$ & {$[1.18,8.72]$} \\
\hline White & Reference & Reference & Reference & Reference \\
\hline \multicolumn{5}{|l|}{ Education } \\
\hline Missing & - & - & 0.13 & {$[0.01,1.07]$} \\
\hline Some high school & - & - & $3 \cdot 39^{* *}$ & {$[2.11,5.44]$} \\
\hline Some college & - & - & $2.05^{*}$ & {$[1.34,3.15]$} \\
\hline College & - & - & Reference & Reference \\
\hline \multicolumn{5}{|l|}{ Income } \\
\hline Missing & - & - & $2.06^{*}$ & {$[1.60,3.98]$} \\
\hline$<\$ 25,000$ & - & - & $4.72^{* *}$ & {$[2.93,7.60]$} \\
\hline$\$ 25,000-\$ 49,999$ & - & - & $1.77^{*}$ & {$[1.04,3.01]$} \\
\hline$\geq \$ 50,000$ & - & - & Reference & Reference \\
\hline Sex (female) & - & - & 1.22 & {$[0.97,1.52]$} \\
\hline \multicolumn{5}{|l|}{ Health insurance } \\
\hline Missing & - & - & Reference & Reference \\
\hline Yes & - & - & $1.40^{*}$ & {$[1.04,1.89]$} \\
\hline \multicolumn{5}{|l|}{ Age } \\
\hline Missing & - & - & 0.90 & {$[0.24,3.38]$} \\
\hline $18-24$ & - & - & $0.05^{* *}$ & {$[0.02,0.10]$} \\
\hline $25-34$ & - & - & $0.13^{* *}$ & {$[0.07,0.23]$} \\
\hline $35-44$ & - & - & $0.45^{* *}$ & {$[0.31,0.67]$} \\
\hline $45-54$ & - & - & 1.35 & {$[0.98,1.87]$} \\
\hline $55-64$ & - & - & $1.41^{*}$ & {$[1.05,1.89]$} \\
\hline $65^{+}$ & - & - & Reference & Reference \\
\hline
\end{tabular}

Note. $\mathrm{OR}=$ odds ratio; $\mathrm{CI}=$ confidence interval.

${ }^{*} p<.01 .{ }^{* *} p<.001$. 
Table 4. Psychological Distress and Heart Attack

\begin{tabular}{|c|c|c|c|c|}
\hline \multirow[b]{2}{*}{ Demographic } & \multicolumn{2}{|c|}{ Model 1} & \multicolumn{2}{|c|}{ Model 2} \\
\hline & OR & $95 \% \mathrm{CI}$ & OR & $95 \% \mathrm{CI}$ \\
\hline \multicolumn{5}{|l|}{ Race/ethnicity } \\
\hline Black & 1.21 & {$[0.50,2.90]$} & 0.80 & {$[0.34,1.85]$} \\
\hline Asian & 0.36 & {$[0.05,2.58]$} & 0.54 & {$[0.07,3.92]$} \\
\hline American Indian & $4.01^{* *}$ & {$[1.78,9.04]$} & 2.32 & {$[0.98,5.48]$} \\
\hline Hispanic & $1.55^{*}$ & {$[1.04,2.33]$} & 0.80 & {$[0.50,1.28]$} \\
\hline Other & $4.09^{*}$ & {$[1.12,14.93]$} & 3.65 & {$[0.87,15.33]$} \\
\hline White & Reference & Reference & Reference & Reference \\
\hline \multicolumn{5}{|l|}{ Education } \\
\hline Missing & - & - & $.00002^{* *}$ & $\begin{array}{c}{[0.000009,} \\
0.00004]\end{array}$ \\
\hline Some high school & - & - & $3.89^{* *}$ & {$[2.31,6.57]$} \\
\hline Some college & - & - & $2.54^{* *}$ & {$[1.68,3.82]$} \\
\hline College & - & - & Reference & Reference \\
\hline \multicolumn{5}{|l|}{ Income } \\
\hline Missing & - & - & $3.93^{* *}$ & {$[1.81,8.56]$} \\
\hline$<\$ 25,000$ & - & - & $9 \cdot 7^{* *}$ & {$[6.22,15.38]$} \\
\hline$\$ 25,000-\$ 49,999$ & - & - & $2.04^{*}$ & {$[1.25,3.33]$} \\
\hline$\geq \$ 50,000$ & - & - & Reference & Reference \\
\hline Sex (female) & - & - & $0.56^{* *}$ & {$[0.40,0.77]$} \\
\hline \multicolumn{5}{|l|}{ Health insurance } \\
\hline Missing & - & - & Reference & Reference \\
\hline Yes & - & - & 1.41 & {$[0.88,2.26]$} \\
\hline \multicolumn{5}{|l|}{ Age } \\
\hline Missing & - & - & 1.04 & {$[0.13,8.23]$} \\
\hline $18-24$ & - & - & $0.009^{* *}$ & {$[0.002,0.04]$} \\
\hline $25-34$ & - & - & $0.11^{* *}$ & {$[0.04,0.25]$} \\
\hline $35-44$ & - & - & 0.54 & {$[0.22,1.30]$} \\
\hline $45-54$ & - & - & 1.07 & {$[0.66,1.72]$} \\
\hline $55-64$ & - & - & 1.41 & {$[0.88,2.27]$} \\
\hline $65^{+}$ & - & - & Reference & Reference \\
\hline
\end{tabular}

Note. $O R=$ odds ratio; $\mathrm{CI}=$ confidence interval.

${ }^{*} p<.01 .{ }^{* *} p<.001$. 
Table 5. Psychological Distress and Angina

\begin{tabular}{|c|c|c|c|c|}
\hline \multirow[b]{2}{*}{ Demographic } & \multicolumn{2}{|c|}{ Model 1} & \multicolumn{2}{|c|}{ Model 2} \\
\hline & OR & $95 \%$ CI & OR & $95 \%$ CI \\
\hline \multicolumn{5}{|l|}{ Race/ethnicity } \\
\hline Black & $0.51^{*}$ & {$[0.27,0.97]$} & $0.37^{*}$ & {$[0.19,0.71]$} \\
\hline Asian & 2.18 & {$[0.54,8.83]$} & 4.06 & {$[0.85,19.27]$} \\
\hline American Indian & $3.82^{* *}$ & {$[1.92,7.63]$} & $2.46^{*}$ & {$[1.24,4.86]$} \\
\hline Hispanic & $2.15^{* *}$ & {$[1.60,2.90]$} & $1.39^{*}$ & {$[1.02,1.90]$} \\
\hline Other & 1.20 & {$[0.75,1.90]$} & 1.08 & {$[0.65,1.79]$} \\
\hline White & Reference & Reference & Reference & Reference \\
\hline \multicolumn{5}{|l|}{ Education } \\
\hline Missing & - & - & 0.40 & {$[0.07,2.26]$} \\
\hline Some high school & - & - & $3.55^{* *}$ & {$[1.93,6.51]$} \\
\hline Some college & - & - & $2.66^{* *}$ & {$[1.54,4.59]$} \\
\hline College & - & - & Reference & Reference \\
\hline \multicolumn{5}{|l|}{ Income } \\
\hline Missing & - & - & 1.17 & {$[0.49,2.78]$} \\
\hline$<\$ 25,000$ & - & - & $4.93^{* *}$ & {$[2.59,9.39]$} \\
\hline$\$ 25,000-\$ 49,999$ & - & - & 1.05 & {$[0.51,2.14]$} \\
\hline$\geq \$ 50,000$ & - & - & Reference & Reference \\
\hline Sex (female) & - & - & 0.74 & {$[0.53,1.03]$} \\
\hline \multicolumn{5}{|l|}{ Health insurance } \\
\hline Missing & - & - & Reference & Reference \\
\hline Yes & - & - & $1.83^{*}$ & {$[1.16,2.88]$} \\
\hline \multicolumn{5}{|l|}{ Age } \\
\hline Missing & - & - & 0.52 & {$[0.13,2.05]$} \\
\hline $18-24$ & - & - & $0.04^{* *}$ & {$[0.01,0.16]$} \\
\hline $25-34$ & - & - & $0.09^{* *}$ & {$[0.04,0.17]$} \\
\hline $35-44$ & - & - & $0.34^{*}$ & {$[0.19,0.61]$} \\
\hline $45-54$ & - & - & 1.21 & {$[0.82,1.80]$} \\
\hline $55-64$ & - & - & $1.51^{*}$ & {$[1.09,2.09]$} \\
\hline $65^{+}$ & - & - & Reference & Reference \\
\hline
\end{tabular}

Note. $\mathrm{OR}=$ odds ratio; $\mathrm{CI}=$ confidence interval.

${ }^{*} p<.01 .{ }^{* *} p<.001$. 
In the final model, we examined psychological distress and history of stroke (Table 6). American Indian $(O R=$ 4.25, 95\% CI $[2.19,8.26])$ and other participants $(O R=2.37$, 95\% CI [1.30, 4.34]) were more likely to experience psychological distress and past history of stroke in comparison to White participants. These relations remained significant with the addition of covariate variables.

Table 6. Psychological Distress and Stroke

\begin{tabular}{|c|c|c|c|c|}
\hline \multirow[b]{2}{*}{ Demographic } & \multicolumn{2}{|c|}{ Model 1} & \multicolumn{2}{|c|}{ Model 2} \\
\hline & OR & $95 \% \mathrm{CI}$ & OR & $95 \% \mathrm{CI}$ \\
\hline \multicolumn{5}{|l|}{ Race/ethnicity } \\
\hline Black & 1.23 & {$[0.66,2.27]$} & 0.81 & {$[0.43,1.56]$} \\
\hline Asian & 0.94 & {$[0.22,3.89]$} & 1.37 & {$[0.33,5.64]$} \\
\hline American Indian & $4.25^{* *}$ & {$[2.19,8.26]$} & $2.45^{*}$ & {$[1.24,4.84]$} \\
\hline Hispanic & 1.19 & {$[0.80,1.78]$} & 0.65 & {$[0.39,1.07]$} \\
\hline Other & $2.37^{*}$ & {$[1.30,4.34]$} & $1.99^{*}$ & {$[1.05,3.74]$} \\
\hline White & Reference & Reference & Reference & Reference \\
\hline \multicolumn{5}{|l|}{ Education } \\
\hline Missing & - & - & 4.49 & {$[0.68,29.55]$} \\
\hline Some high school & - & - & $3.50^{* *}$ & {$[2.03,6.02]$} \\
\hline Some college & - & - & $2.35^{* *}$ & {$[1.57,3.50]$} \\
\hline College & - & - & Reference & Reference \\
\hline \multicolumn{5}{|l|}{ Income } \\
\hline Missing & - & - & $3.66^{* *}$ & {$[1.82,7.33]$} \\
\hline$<\$ 25,000$ & - & - & $9.76^{* *}$ & {$[5.6,17.01]$} \\
\hline$\$ 25,000-\$ 49,999$ & - & - & $2.97^{* *}$ & {$[1.69,5.22]$} \\
\hline$\geq \$ 50,000$ & - & - & Reference & Reference \\
\hline Sex (female) & - & - & 0.84 & {$[0.62,1.14]$} \\
\hline \multicolumn{5}{|l|}{ Health insurance } \\
\hline Missing & - & - & Reference & Reference \\
\hline Yes & - & - & 1.5 & {$[0.85,2.65]$} \\
\hline \multicolumn{5}{|l|}{ Age } \\
\hline Missing & - & - & 0.56 & {$[0.11,2.71]$} \\
\hline $18-24$ & - & - & $.16^{*}$ & {$[0.04, .64]$} \\
\hline $25-34$ & - & - & $.14^{* *}$ & {$[0.06, .34]$} \\
\hline $35-44$ & - & - & .57 & {$[0.31,1.04]$} \\
\hline $45^{-54}$ & - & - & 1.4 & {$[0.85,2.31]$} \\
\hline $55-64$ & - & - & $1.56^{*}$ & {$[1.06,2.30]$} \\
\hline $65^{+}$ & - & - & Reference & Reference \\
\hline
\end{tabular}

Note. $\mathrm{OR}=$ odds ratio; $\mathrm{CI}=$ confidence interval.

${ }^{*} p<.01 .{ }^{* *} p<.001$. 


\section{Discussion}

Our results indicate that ethnic/minority groups are more likely to have comorbid mental health and medical conditions, specifically psychological distress and diabetes, angina, and history of heart attack or stroke in comparison to White participants. American Indian and Hispanic participants were more likely to have comorbid conditions, while results for Asian participants were nonsignificant and Black participants were less likely to have psychological distress and angina. The adjusted odds ratios that remained significant were related to diabetes, angina, and history of stroke, results which confirm previous studies indicating strong associations between hypertension and discrimination (Carliner et al., 2014). Covariate variables associated with comorbid conditions, included education level, household income, and age. From the historical record and previous studies, we know that discrimination plays a role in educational attainment and income levels, which alludes to the greater impact of discrimination on not just health, but other factors that influence health including social determinants of health (Knapp \& Hall, 2018; Kolak et al., 2020). Importantly though, even when controlling for these other known social determinants of health, participants' race remained a significant predictor. This finding is similar to results from other studies which have shown that even if minority participants had the same sociodemographic characteristics as Whites, health care disparities would remain (Langellier et al., 2016).

The increased risk of comorbid medical and mental health issues seen for some of the racial/ethnic groups in this study could be attributed to historical and on-going discrimination, in addition to other contributing factors (e.g. genetics, health risk behaviors). With this in mind it is not surprising to see that Native Americans were two to three times more likely to have psychological distress comorbidity with diabetes, stroke, and angina in unadjusted results, given how this group has been historically and currently treated in the Unites States (Findling et al., 2019). Stress arising from discrimination is shown to have a direct impact on both physical and mental health through physiological pathways (Carter et al., 2017; Suvarna et al., 2020). Some researchers have theorized that individuals exposed to chronic stressors (like discrimination stress) are more likely to engage in poor health behaviors, including smoking, drinking, drug use, and overeating as these are accessible coping strategies for dealing with stress (Boateng-Poku et al., 2020; Jackson et al., 2010). However, as ongoing strategies for stress management, these behaviors are maladaptive and may lead to the higher rates of chronic diseases.

Additionally, structural inequalities in neighborhoods and health care systems often mean racial/ethnic minorities are more likely to have difficulty in accessing care and are disproportionately more likely to receive poorer quality care (Alegría et al., 2008). Even when care is accessed for medical services, there is less chance that minorities will receive mental health care than for White patients (Alegría et al., 2008). Furthermore, studies have shown that people of color may be less likely to seek care for depressive symptoms due to past negative experiences with mental health providers (Diamant et al., 2004; Whaley, 2001a, 2001b). Other researchers examining comorbidity in these populations have theorized that being a member of a racial/ethnic minority and living with a mental illness may lead to a "double disadvantage" or "double jeopardy" situation where the individual belongs to two disadvantaged groups, and this confers worse physical health and a shorter life expectancy (Dhingra et al., 2011).

Some of our findings did not show significant differences between minority populations and Whites for comorbid psychological distress and the medical conditions examined. However, past studies suggest that the burden of these disorders may be greater in racial/ethnic minorities. For example, among African American and Caribbean Black populations, depression is usually untreated, more severe, and results in greater functional impairment than for White patients (Williams et al., 2007). So, while there may not be a greater risk for having this comorbidity, there may be an increased burden on minority groups. 


\section{Strengths and Limitations}

A strength of this study is its examination of psychological distress and disease together, which is an understudied topic. The use of the Kessler Psychological Distress Scale is another strength of our study as it assesses the level of symptomology often associated with mental health disorders as opposed to relying on a medical diagnosis, which as we have discussed some racial and ethnic groups are less likely to obtain. A limitation of our study is that it did not examine the level of health burden (i.e., the overall psychological and economic impact of being diagnosed with a specific illness) on the individual. We suggest that future studies examining comorbidity of mental health and medical disorders incorporate this variable as an outcome to better understand the impact on these populations. Other limitations of this study include that data are selfreported and not based on medical records, so the accuracy of the medical diagnosis or psychological symptoms experienced cannot be confirmed. Additionally, while the diseases we reported on are all chronic disorders requiring ongoing follow-up care, the survey does not distinguish between Type 1 and Type 2 diabetes. It is possible that some individuals previously diagnosed with Type 2 diabetes no longer have a current diagnosis. Additionally, as Type 1 diabetes starts in childhood and operates through a different mechanism than Type 2, it is unlikely that Type 1 is causally related to discrimination in the same ways as Type 2 or the other outcomes examined in this study.

Finally, due to limits of the data, we are using an ethnic inferred model whereby we are only measuring racial/ethnic minority group membership and not assessing the level of discrimination experienced by these groups, but rather inferring discriminatory stress based on group membership (Phinney \& Landin, 1998). An ethnic inferred model extends the associations established in the literature between membership in a particular racial/ethnic group and certain cultural values or experiences particular to that group. In the current study by controlling for socioeconomic status factors, racial/ethnic group membership is used as an indicator of discrimination, but there was no direct measure of discrimination for the BRFSS data extracted for this analysis. Future studies should measure discrimination, and the association between discrimination and comorbid health outcomes.

\section{Conclusion and Implications}

In conclusion, we believe that as a result of the higher levels of discrimination faced by racial/ethnic minority groups in the United States, these populations may be more likely to experience comorbidity of mental health and medical issues. Given the potential reciprocal relationship between these mental health and medical disorders, clinicians should work to ensure that patients receive simultaneous treatment. Increased screening in primary care settings, referrals to mental health services, and overall better integration of physical and mental health treatment may reduce the potentially disproportionate burden of these comorbidities on racial/ethnic minority patients. Future research should continue to investigate the prevalence of comorbid mental health and medical disorders among racial/ethnic minorities, measure the burden of these comorbidities on patients, and assess the level of discrimination experienced by these groups to better understand the association between discrimination stress, including its impact on health care quality and access.

\section{References}

Alegría, M., Chatterji, P., Wells, K., Cao, Z., Chen, C., Takeuchi, D., ... Meng, X.-L. (2008). Disparity in depression treatment among racial and ethnic minority populations in the United States. Psychiatric Services, 59(11), 1264-1272. https://doi.org/10.1176/ps.2008.59.11.1264

American Diabetes Association. (2018). Economic Costs of Diabetes in the U.S. in 2017. Diabetes Care, 41(5), 917-928. https://doi.org/10.2337/dci18-0007 
Boateng-Poku, A., Benca-Bachman, C. E., Najera, D. D., Whitfield, K. E., Taylor, J. L., Thorpe, R. J., \& Palmer, R. H. C. (2020). The role of social support on the effects of stress and depression on African American tobacco and alcohol use. Drug and Alcohol Dependence, 209, 107926.

Bradley, S. M., \& Rumsfeld, J. S. (2015). Depression and cardiovascular disease. Trends in Cardiovascular Medicine, 25(7), 614-622. https://doi.org/10.1016/J.TCM.2015.02.002

Carliner, H., Collins, P., Cabassa, L., McNallen, A., Joestl, S. S., \& Lewis-Fernández, R. (2014). Prevalence of cardiovascular risk factors among racial and ethnic minorities with schizophrenia spectrum and bipolar disorders: A critical literature review. Comprehensive Psychiatry, 55(2), 233-247. https://www.sciencedirect.com/science/article/pii/So010440X13002915

Carter, R. T., Lau, M. Y., Johnson, V., \& Kirkinis, K. (2017). Racial discrimination and health outcomes among racial/ethnic minorities: A meta-analytic review. Journal of Multicultural Counseling and Development, 45(4), 232-259.

Das-Munshi, J., Stewart, R., Morgan, C., Nazroo, J., Thornicroft, G., \& Prince, M. (2016). Reviving the "double jeopardy" hypothesis: physical health inequalities, ethnicity and severe mental illness. The British Journal of Psychiatry, 209(3), 183-185. https://www.cambridge.org/core/journals/the-britishjournal-of-psychiatry/article/reviving-the-double-jeopardy-hypothesis-physical-health-inequalitiesethnicity-and-severe-mental-illness/9C117D16D523C63BAA958858A31AC5F

Dhingra, S. S., Zack, M. M., Strine, T. W., Druss, B. G., Berry, J. T., \& Balluz, L. S. (2011). Psychological distress severity of adults reporting receipt of treatment for mental health problems in the BRFSS. Psychiatric Services, 62(4), 396-403. https://doi.org/10.1176/ps.62.4.pss6204 0396

Diamant, A. L., Hays, R. D., Morales, L. S., Ford, W., Calmes, D., Asch, S., ... Gelberg, L. (2004). Delays and unmet need for health care among adult primary care patients in a restructured urban public health system. American Journal of Public Health, 94(5), 783-789. https://doi.org/10.2105/AJPH.94.5.783

Druss, B. G., Chair, R. C., \& Walker, E. R. (2011). Mental disorders and medical comorbidity. http://www.integration.samhsa.gov/workforce/mental disorders and medical comorbidity.pdf

Earnshaw, V. A., Rosenthal, L., Carroll-Scott, A., Santilli, A., Gilstad-Hayden, K., \& Ickovics, J. R. (2016). Everyday discrimination and physical health: Exploring mental health processes. Journal of Health Psychology, (10), 2218-2228.

Findling, M. G., Casey, L. S., Fryberg, S. A., Hafner, S., Blendon, R. J., Benson, J. M., Sayde, J. M., \& Miller, C. (2019). Discrimination in the United States: Experiences of Native Americans. Health Services Research, 54(S2), 1431-1441.

Garcini, L. M., Peña, J. M., Galvan, T., Fagundes, C. P., Malcarne, V., \& Klonoff, E. A. (2017). Mental disorders among undocumented Mexican immigrants in high-risk neighborhoods: Prevalence, comorbidity, and vulnerabilities. Journal of Consulting and Clinical Psychology, 85(10), 927-936. https://doi.org/10.1037/ccpooo0237

Gavin, A., Grote, N., Conner, K., \& Fentress, T. (2019). Racial discrimination and preterm birth among African American women: The important role of posttraumatic stress disorder. Journal of Health Disparities Research and Practice, 11(4), 91-109.

Gee, G. C., Spencer, M. S., Chen, J., \& Takeuchi, D. (2007). A nationwide study of discrimination and chronic health conditions among Asian Americans. American Journal of Public Health, 97(7), 1275-1282. https://doi.org/10.2105/AJPH.2006.091827

Goodell, S., Druss, B. G., \& Walker, E. R. (2011). Mental disorders and medical comorbidity (Policy Brief No. 21). 
https://www.researchgate.net/profile/Elizabeth Walker12/publication/51220912 Mental Disorder $\underline{\mathrm{s} \text { and Medical Comorbidity/links/0a85e53c973139cf16000000.pdf }}$

Jackson, J. S., Knight, K. M., \& Rafferty, J. A. (2010). Race and unhealthy behaviors: chronic stress, the HPA axis, and physical and mental health disparities over the life course. American Journal of Public Health, 10O(5), 933-939. https://doi.org/10.2105/AJPH.2008.143446

Kessler, R. C., Barker, P. R., Colpe, L. J., Epstein, J. F., Gfroerer, J. C., Hiripi, E., Howes, M. J., Normand, S.L. T., Manderscheid, R. W., Walters, E. E., \& Zaslavsky, A. M. (2003). Screening for serious mental illness in the general population. Archives of General Psychiatry, 6o(2), 184-189.

Kessler, R. C., Mickelson, K. D., \& Williams, D. R. (1999). The prevalence, distribution, and mental health correlates of perceived discrimination in the United States. Journal of Health and Social Behavior, 4O(3), 208-230. https://www-jstor-org.proxy-um.researchport.umd.edu/stable/pdf/2676349.pdf

Knapp, T., \& Hall, L. (2018). The social determinants of health in a community context: Lessons for sociological practice. Journal of Applied Social Science, 12(2), 67-81.

Kolak, M., Bhatt, J., Park, Y. H., Padrón, N. A., \& Molefe, A. (2020). Quantification of neighborhood-level social determinants of health in the continental United States. JAMA Network Open, 3(1), e1919928.

Langellier, B. A., Chen, J., Vargas-Bustamante, A., Inkelas, M., \& Ortega, A. N. (2016). Understanding healthcare access and utilization disparities among Latino children in the United States. Journal of Child Health Care, 2O(2), 133-144.

Little, R. J. A. (1988). A test of missing completely at random for multivariate data with missing values. Journal of the American Statistical Association, 83(404), 1198-1202. https://doi.org/10.1080/01621459.1988.10478722

Mangurian, C., Newcomer, J. W., Modlin, C., \& Schillinger, D. (2016). Diabetes and cardiovascular care among people with severe mental illness: A literature review. Journal of General Internal Medicine, 31(9), 1083-1091. https://doi.org/10.1007/s11606-016-3712-4

Miller, A. H., \& Raison, C. L. (2016). The role of inflammation in depression: From evolutionary imperative to modern treatment target. Nature Reviews Immunology, 16(1), 22-34. https://doi.org/10.1038/nri.2015.5

Mouzon, D. M., Taylor, R. J., Woodward, A. T., \& Chatters, L. M. (2017). Everyday racial discrimination, everyday non-racial discrimination, and physical health among African-Americans. Journal of Ethnic \& Cultural Diversity in Social Work, 26(1-2), 68-80.

National Center for Health Statistics. (2016). Health, United States, 2015: With special feature on racial and ethnic health disparities. http://www.ncbi.nlm.nih.gov/pubmed/27308685

Orsi, J. M., Margellos-Anast, H., \& Whitman, S. (2010). Black-White health disparities in the United States and Chicago: A 15-year progress analysis. American Journal of Public Health, 10o(2), 349-356. https://doi.org/10.2105/AJPH.2009.165407

Phinney, J. S., \& Landin, J. (1998). Research paradigms for studying ethnic minority families within and across groups. In C. McLoyd \& L. Steinberg (Eds.), Studying minority adolescents: Conceptual, methodological, and theoretical issues (pp. 89-109). Lawrence Erlbaum. https://psycnet.apa.org/record/1998-07814-004

Pool, L. R., Ning, H., Lloyd-Jones, D. M., \& Allen, N. B. (2017). Trends in racial/ethnic disparities in cardiovascular health among US adults from 1999-2012. Journal of the American Heart Association, 6(9), e006027.

Roy, T., \& Lloyd, C. E. (2012). Epidemiology of depression and diabetes: A systematic review. Journal of Affective Disorders, 142 Suppl, S8-21. https://doi.org/10.1016/So165-0327(12)70004-6 
Rustad, J. K., Musselman, D. L., \& Nemeroff, C. B. (2011). The relationship of depression and diabetes: pathophysiological and treatment implications. Psychoneuroendocrinology, 36(9), 1276-1286. https://doi.org/10.1016/j.psyneuen.2011.03.005

Silva, N. M. (2014). The Behavioral Risk Factor Surveillance System. The International Journal of Aging and Human Development, 79(4), 336-338. https://doi.org/10.1177/0091415015574184

Sjöström, L., Lindroos, A.-K., Peltonen, M., Torgerson, J., Bouchard, C., Carlsson, B., ... Wedel, H. (2004). Lifestyle, diabetes, and cardiovascular risk factors 10 years after bariatric surgery from the departments of body composi-tion and metabolism. New England Journal of Medicine, 351(26), 2683-2693.

Stamler, J., Vaccaro, O., Neaton, J. D., \& Wentworth, D. (1993). Diabetes, other risk factors, and 12-yr cardiovascular mortality for men screened in the multiple risk factor intervention trial. Diabetes Care, 16(2), 434-444. http://www.siditalia.it/pdf/Diabete-ed-Arterosclerosi/MRFIT Diab care 1993.pdf

Suvarna, B., Suvarna, A., Phillips, R., Juster, R.-P., McDermott, B., \& Sarnyai, Z. (2020). Health risk behaviours and allostatic load: A systematic review. Neuroscience \& Biobehavioral Reviews, 108, 694-711.

Watkins, D. C., Assari, S., \& Johnson-Lawrence, V. (2015). Race and ethnic group differences in comorbid major depressive disorder, generalized anxiety disorder, and chronic medical conditions. Journal of Racial and Ethnic Health Disparities, 2, 385-394. https://doi.org/10.1007/s40615-015-0085-z

Whaley, A. L. (2001a). Cultural mistrust and mental health services for African Americans. The Counseling Psychologist, 29(4), 513-531. https://doi.org/10.1177/0011000001294003

Whaley, A. L. (2001b). Cultural mistrust of White mental health clinicians among African Americans with severe mental illness. American Journal of Orthopsychiatry, 71(2), 252-256. https://doi.org/10.1037/0002-9432.71.2.252

Williams, D. R. (2018). Stress and the mental health of populations of color: Advancing our understanding of race-related stressors. Journal of Health and Social Behavior, 59(4), 466-485.

Williams, D. R., González, H. M., Neighbors, H., Nesse, R., Abelson, J. M., Sweetman, J., \& Jackson, J. S. (2007). Prevalence and distribution of major depressive disorder in African Americans, Caribbean Blacks, and non-Hispanic Whites: Results from the National Survey of American Life. Archives of General Psychiatry, 64(3), 305-315.

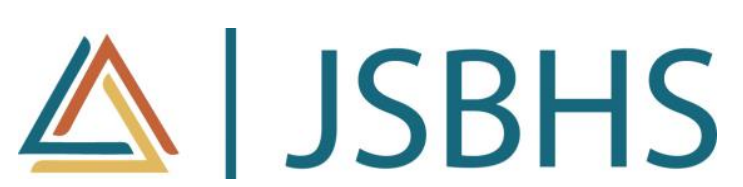

The Journal of Social, Behavioral, and Health Sciences (JSBHS), co-sponsored by the College of Health Sciences and the College of Social and Behavioral Sciences at Walden University, is a peer-reviewed, online, interdisciplinary journal focusing on theoretically-based research that addresses contemporary national and international issues. JSBHS articles include peer-reviewed research reports, brief resports, comprehensive literature reviews, books reviews, and student research. 